\title{
Possible impact of adopting extreme hypofractionation after FAST Forward trial publication
}

\author{
Gustavo Nader Marta1,2* (1)
}

Breast cancer is the most common type of malignant tumor and the main cause of cancer mortality in women worldwide ${ }^{1}$. In general, a multidisciplinary therapeutic approach comprising surgical, medical, and radiation oncology is needed for the optimal management of breast cancer; this combination is correlated with improved overall survival rates ${ }^{2}$. After breast-conserving surgery or mastectomy, post-operative radiation therapy decreases cancer mortality and loco-regional relapse rates in most breast cancer patients ${ }^{3,4}$.

Historically, conventionally-used radiation doses ranged from 50 to $50.4 \mathrm{~Gy}$ in fractions of 1.8 to 2.0 Gy over the course of 25 to 28 days. This dose was empirically confirmed based on the hypothesis this schedule was safe and effective. This idea was enhanced by studies that assessed early skills of the moderately hypofractionated whole breast irradiation practice; however, these reports used obsolete and incorrect radiobiological models and outmoded devices of treatment delivery and calculation, hence exhibiting unacceptably high rates of side effects ${ }^{5,6}$.

Nonetheless, other groups posteriorly provided assessments of normal-tissue damage and fraction size in breast tumors developing the current protocols of moderately hypofractionated wholebreast irradiation which involved fraction ranges up to nearby $3 \mathrm{~Gy}$ pooled with an abridged total dose delivered over a shorter period of time (e.g., three weeks). This schedule attained radiobiological equivalence to the conventional radiation $\operatorname{doses}^{7,8}$. Long term follow-up in large clinical trials sustained the efficacy and safety of the moderately hypofractionated whole breast irradiation practices ${ }^{9-11}$. In fact, the all-purpose engagement of hypofractionation can serve to reduce the therapeutic period, decreasing the total number of fractions, and offering a more convenient treatment schedule for patients. Moreover, hypofractionation can also increase patients' access to oncology centers (particular importance for countries with limited resources with restricted radiation therapy assets), decrease indirect costs associated with work breaks and travel to the medical care center, and reduce treatment costs ${ }^{12,13}$.

Now, the first tumor-results associated endpoint assessment from the FAST Forward trial was published, which offers a treatment extreme hypofractionated schedule of just five fractions in five consecutive days for patients with early breast cancer ${ }^{14}$. In this timely, multicenter, non-inferiority, prospective phase 3 randomised trial, 4,096 patients ( $\mathrm{pT} 1-3$, $\mathrm{pN} 0-1, \mathrm{M} 0$ ) were randomly allocated into three groups to receive moderated hypofractionated RT (15×2.67 Gy; over three weeks) or two schedules of ultra-hypofractionated RT over one week $(5 \times 5.2$ Gy - 26 Gy or $5 \times 5.4$ Gy - 27 Gy) directed to the whole breast or chest wall. No statistically significant difference in the 5-year cumulative incidence of breast tumor relapse among the groups was found $(2.3 \%$ in moderated hypofractionated RT versus $2.0 \%$ in 27 Gy versus $1.5 \%$ in 26 Gy). Likewise, the acute and late adverse events were similar in the groups, apart from a higher late normal tissue effect in the 27 Gy RT arm. We would therefore certainly not consider the highlighted results for 26 Gy versus 40 Gy for breast distortion and breast/chest wall oedema clinically relevant. The other highlighted result, the one for breast induration outside the tumor bed, is statistically significant at $\mathrm{p}<0.0001$; however, it is hard to maintain for clinical significance with the demonstrated 5-year moderate/marked events rates only $0.1 \%$ in 40 Gy and $1.9 \%$ in 26 Gy. In fact, the side effects are properly low across all of the endpoints, regardless the treatment schedule ${ }^{14}$. Hence, it should be recognized that the clinical outcomes of this trial could support the adoption of 26 Gy in 5 consecutive daily fractions as a treatment option for most of early breast cancer patients in the near future.

\footnotetext{
${ }^{1}$ Hospital Sírio-Libanês, Department of Radiation Oncology - São Paulo (SP), Brazil.

${ }^{2}$ The Latin American Cooperative Oncology Group - Porto Alegre (RS), Brazil.

*Corresponding author: gustavonmarta@gmail.com

Conflicts of interest: the authors declare there are no conflicts of interest. Funding: none.

Received on September 19, 2020. Accepted on September 20, 2020.
} 
Despite patients with ductal carcinoma in situ (DCIS) were not a formal inclusion criterion in the FAST Forward trial, extreme hypofractionated ones can also be considered, as there is no radiobiological concern regarding why five fractions are expected to be less effective in the DCIS setting ${ }^{14}$. This is coherent with a previous policy which adopted moderately hypofractionated irradiation for DCIS once the results of clinical trials that assessed patients with invasive breast cancer have been extrapolated to the context of in situ disease ${ }^{15-18}$.

Along the same reasoning lines, extreme hypofractionated can be considered in patients who received both implant and autologous reconstructions as acute and late normal tissue site effects overall were similar in five fractions (26 Gy group) and 15 fractions in the FAST Forward trial, although numbers of reconstructions were small. In other words, the results of the FAST Forward trial ${ }^{14}$ showed that most normal tissue adverse events that are frequently associated with radiation-related toxicities in implant and autologous breast reconstructions (e.g., fibrosis, skin retraction, and breast shrinkage) were similar in patients who underwent five fractions (26 Gy group) or 15 fractions. Additionally, no randomized phase III trial has yet validated the use of a conventional or moderately hypofractionated radiation doses after breast reconstruction. Historically, in empirical studies, the conventional dose has been used whenever breast-reconstruction techniques were described ${ }^{19}$. In recent decades, in clinical practice, once a treatment has been performed with conventional doses, there has been a simple incorporation of reconstructive surgeries.

When indicated, sequential boost can be added to $26 \mathrm{~Gy}$ in five fractions whole breast RT. In the FAST Forward trial, 25\% of patients received a sequential boost of five to eight fractions of $2 \mathrm{~Gy}$ and were well tolerated. More will emerge with the FAST Forward nodal sub-study which is yet to report and where all patients are node-positive by definition. The adoption of an extreme hypofractionated schedule for higher risk breast cancer patients still need to be evaluated.

Since the majority of patients in the FAST Forward trial (14) are relatively low risk cases, we should be very careful when changing guidelines based on one clinical trial in particular for use in the higher risk patients. This is the reason why the UK group has a call-out for treatment de-escalation studies FAST Forward trial HIGH focusing on patients with high-risk disease, including those requiring internal mammary lymph nodes treatment.

Finally, the economic issues behind new ways of delivering radiation therapy need to be discussed. How to deal with the possible financial loss on reimbursement due to adopting extreme-hypofractionated radiation therapy schedules? While in countries like The Netherlands, Italy, and the UK (where reimbursement is largely independent from the number of fractions), moderate hypofractionated breast irradiation practice is used by the majority of centers, in the more reimbursement-driven models with payment-per-fraction countries, including Germany, France, Portugal and the USA, a lot of reluctance exists towards applying moderate hypofractionation in daily practice. The possible financial loss induced by the reduction in per-patient income due to fractionation-based reimbursement could be compensated by an evolution of the reimbursement model from a fee-for-service system to a bundled payment system based on quality parameters. It is important to encourage payers to abandon payment per fraction as the use of moderate radiation therapy and extreme-hypofractionation for breast cancer patients is a concrete reality.

\section{REFERENCES}

1. Siegel RL, Miller KD, Jemal A. Cancer statistics, 2019. CA Cancer J Clin. 2019;69(1):7-34. https://doi.org/10.3322/caac.21551

2. Kesson EM, Allardice GM, George WD, Burns HJ, Morrison DS. Effects of multidisciplinary team working on breast cancer survival: retrospective, comparative, interventional cohort study of 13722 women. BMJ. 2012;344:e2718. https://doi. org/10.1136/bmj.e2718

3. Early Breast Cancer Trialists' Collaborative Group (EBCTCG); Darby S, McGale P, Correa C, Taylor C, Arriagada R, et al. Effect of radiotherapy after breast-conserving surgery on 10-year recurrence and 15-year breast cancer death: metaanalysis of individual patient data for 10,801 women in 17 randomised trials. Lancet. 2011;378(9804):1707-16. https:// doi.org/10.1016/S0140-6736(11)61629-2

4. EBCTCG (Early Breast Cancer Trialists' Collaborative Group); McGale P, Taylor C, Correa C, Cutter D, Duane F, et al. Effect of radiotherapy after mastectomy and axillary surgery on 10-year recurrence and 20-year breast cancer mortality: meta-analysis of individual patient data for 8135 women in 22 randomised trials. Lancet. 2014;383(9935):2127-35. https://doi.org/10.1016/S0140-6736(14)60488-8

5. Overgaard M, Bentzen SM, Christensen JJ, Madsen EH The value of the NSD formula in equation of acute and late radiation complications in normal tissue following 2 and 5 fractions per week in breast cancer patients treated with postmastectomy irradiation. Radiother Oncol. 1987;9(1):1-11. https://doi.org/10.1016/s0167-8140(87)80213-x

6. Johansson S, Svensson H, Denekamp J. Dose response and latency for radiation-induced fibrosis, edema, and neuropathy in breast cancer patients. Int J Radiat Oncol Biol Phys. 2002;52(5):120719. https://doi.org/10.1016/s0360-3016(01)02743-2

7. Whelan T, MacKenzie R, Julian J, Levine M, Shelley W, Grimard $\mathrm{L}$, et al. Randomized trial of breast irradiation schedules after lumpectomy for women with lymph node-negative breast cancer. J Natl Cancer Inst. 2002;94(15):1143-50. https://doi. org/10.1093/jnci/94.15.1143 
8. Yarnold J, Ashton A, Bliss J, Homewood J, Harper C, Hanson $J$, et al. Fractionation sensitivity and dose response of late adverse effects in the breast after radiotherapy for early breast cancer: long-term results of a randomised trial. Radiother Oncol. 2005;75(1):9-17. https://doi.org/10.1016/j. radonc.2005.01.005

9. Valle LF, Agarwal S, Bickel KE, Herchek HA, Nalepinski DC, Kapadia NS. Hypofractionated whole breast radiotherapy in breast conservation for early-stage breast cancer: a systematic review and meta-analysis of randomized trials. Breast Cancer Res Treat. 2017;162(3):409-17. https://doi.org/10.1007/ s10549-017-4118-7

10. Whelan TJ, Pignol JP, Levine MN, Julian JA, MacKenzie R, Parpia S, et al. Long-term results of hypofractionated radiation therapy for breast cancer. N Engl J Med. 2010;362(6):513-20. https://doi.org/10.1056/NEJMoa0906260

11. Marta GN, Poortmans P. Moderately hypofractionated breast radiation therapy: is more evidence needed? Lancet Oncol. 2019;20(5):e226. https://doi.org/10.1016/S14702045(19)30078-6

12. Lievens $Y$, van den Bogaert W, Kesteloot K. Activity-based costing: a practical model for cost calculation in radiotherapy. Int J Radiat Oncol Biol Phys. 2003;57(2):522-35. https://doi. org/10.1016/s0360-3016(03)00579-0

13. Khan AJ, Rafique R, Zafar W, Shah C, Haffty BG, Vicini F, et al. Nation-scale adoption of shorter breast radiation therapy schedules can increase survival in resource constrained economies: results from a markov chain analysis. Int J Radiat Oncol Biol Phys. 2017;97(2):287-95. https://doi.org/10.1016/j. ijrobp.2016.10.002
14. Brunt AM, Haviland JS, Wheatley AD, Sydenham MA, Alhasso A, Bloomfield DJ, et al. Hypofractionated breast radiotherapy for 1 week versus 3 weeks (FAST-Forward): 5 -year efficacy and late normal tissue effects results from a multicentre, non-inferiority, randomised, phase 3 trial. Lancet. 2020;395(10237):1613-26. https://doi.org/10.1016/S0140-6736(20)30932-6

15. Smith BD, Bellon JR, Blitzblau R, Freedman G, Haffty B, Hahn $C$, et al. Radiation therapy for the whole breast: executive summary of an American Society for Radiation Oncology (ASTRO) evidence-based guideline. Pract Radiat Oncol. 2018;8(3):145-52. https://doi.org/10.1016/j.prro.2018.01.012

16. SBRT, Brazilian Society of Radiotherapy, Freitas NMA, Rosa AA, Marta GN, Hanna SA, et al. Recommendations for hypofractionated whole-breast irradiation. Rev Assoc Med Bras (1992). 2018;64(9):770-7. https://doi.org/10.1590/18069282.64.09.770

17. Lansu JT, Essers M, Voogd AC, Luiten EJ, Buijs C, Groenendaal $\mathrm{N}$, et al. The influence of simultaneous integrated boost, hypofractionation and oncoplastic surgery on cosmetic outcome and PROMs after breast conserving therapy. Eur J Surg Oncol. 2015;41(10):1411-6. https://doi.org/10.1016/j. ejso.2015.07.011

18. Bloomfield DJ, Core Group facilitated by The Royal College of Radiologists. Development of postoperative radiotherapy for breast cancer: UK consensus statements - a model of patient, clinical and commissioner engagement? Clin Oncol (R Coll Radiol). 2017;29(10):639-41. https://doi.org/10.1016/j. clon.2017.06.011

19. Bostwick J. Reconstruction of the breast. Acta Chir Belg. 1980;79(2):125-9. PMID: 7435093 